\title{
A Proposal for the Description of Individual Course Units
}

\author{
http://dx.doi.org/10.3991/ijep.v3iS1.2420 \\ João Paulo Barros ${ }^{1,2}$, Luís Gomes ${ }^{2,3}$, and Luís Garcia ${ }^{1}$ \\ ${ }^{1}$ Escola Superior de Tecnologia e Gestão, Beja, Portugal \\ ${ }^{2}$ UNINOVA-CTS, Monte de Caparica, Portugal \\ ${ }^{3}$ Universidade Nova de Lisboa, Monte de Caparica, Portugal
}

\begin{abstract}
The description of individual course units is here presented as a privileged way to improve course quality by fostering teacher reflection. To that end, the paper presents a structured way to specify the several parts that compose the course unit descriptions. The most important parts are made strongly interconnected as a way to maximize coherence and force additional reflection during course design. The paper presents a concrete template that expands the recommendations and course unit data present in the ECTS User's Guide. Besides including the usual course data, the template guides the course designer towards the specification of several alignments between the data. These alignments make the course unit descriptions self justifying and internally coherent. Additionally, a grading strategy is briefly presented and the intended learning outcomes are classified according to the European Qualification Framework for Lifelong Learning.
\end{abstract}

Index Terms-course description; learning outcomes; assessment; grading; ECTS; alignment; curricula design; EQF.

\section{INTRODUCTION}

Presently, the importance attributed to the specification of learning outcomes or, more precisely, intended learning outcomes, has been growing. This is easily demonstrated by the number of official documents where they are mentioned or recommended (e.g. [1-5]). In the European context, the Bologna process, following the Bologna declaration [6] has contributed to a much wider preoccupation with learning outcomes or, more precisely, intended learning outcomes (ILOs) and respective coherence with other course data. This is reflected in the ECTS User's Guide [1], where the "description of individual course units" explicitly includes "learning outcomes of the course unit". Yet, this has given rise to another problem: how to educate teachers on the correct use of learning outcomes for improving student learning? A good answer must be available for this question so that the specification of learning outcomes is not regarded as simply another bureaucratic burden. This can have, as a consequence, the uselessness of those learning outcomes, as they are not really understood or even applied. This misuse can happen at both levels: the specification level; the application level. Many good resources about learning outcomes are available (e.g. [5, 7, 8, 9]) but, as usual in many educational related subjects, they attract mainly the teachers who need them the least. In this paper, we propose the use of a template for a structured course unit description, which "forces" all teachers, while course designers, to specify and reflect on the use of intended learning outcomes. To that end the template demands the specification of several dependencies between its main parts. To those dependencies we call alignments, which is the usual term. Regarding the course unit description those alignments maximize internal coherence and, most importantly, they guide and force deep reflection by the course designer. Hence, the intended learning outcomes become starting points to improve the course design, and, indirectly, the student results. They also become deeply interconnected with other course data, thus strengthening their perceived applicability and usefulness.

Regarding the related literature, the proposed template includes the recommendations in the ECTS User's Guide regarding the "Description of individual course units". It also includes the "double alignment" concept (e.g. [8, 9]) part of "constructive alignment" [9]. This paper, which revises and expands a previous work [10], follows a stepwise approach that starts from the ECTS User's Guide recommended data. After, it presents each part of the template. Section II presents the first step: the general information based on the ECTS User's Guide. Section III shows how to align learning outcomes to contents and these to study material. Section IV discusses an especially relevant alignment: the one between learning outcomes and assessment. After, Section $\mathrm{V}$ presents the alignment between assessment and teaching and learning activities. Next, Section VI briefly discusses how to achieve the desirable coherence and alignment between assessment and grading. To that end, a stepwise grading method is briefly presented. Finally, Section VII concludes.

\section{Motivation}

As already stated, several official documents explicitly recommend the use of ILOs. Hence, the first goal of the presented template is the compliance with those recommendations.

Additionally, the most important motivation comes from the anecdotal evidence that many teachers are not well motivated to effectively use those recommendations and take the best advantage of the specification of those ILOs. Hence, this paper proposes the use of the "description of individual course units", sometimes called course curriculum as a means to take advantage of the ILOs specification as a starting point in curricula design. That is achieved trough the specification of internal interdependencies. In the end, these create a global coherence in the whole course unit, which should foster 
an improved learning environment and better learning experiences.

Another motivation for the use of more complete descriptions at the course unit level, is the creation of a solid platform for the specification of further alignments at additional levels: namely between course units and the whole programme, between the programme and the "class of programmes" (bachelor, masters, etc), and also between those classes and the general institutional goals, namely its mission and regulations.

Finally, as in the ECTS User's Guide, another important motivational factor is the improvement in the information available to the students. A more complete course unit information is better not only at informing the student but also at guiding the teachers. Intended Learning Outcomes and their interconnections to other parts, namely assessment and contents offer the best way to give students the answer to the famous question: why are we studying/doing this?

The following section starts the presentation of the template for the description of individual course units.

\section{GENERAL DATA,}

The ECTS User's Guide already specifies a large set of data that should be present in the description of each curricular unit [1, p. 28] (the ones in bold are object of further discussion in this paper):

1. Course unit title;

2. Course unit code;

3. Type of course unit (compulsory, optional);

4. Level of course unit (e.g. first, second or third cycle; sub-level if applicable);

5. Year of study (if applicable);

6. Semester/trimester when the course unit is delivered;

7. Number of ECTS credits allocated;

8. Name of lecturer(s);

9. Learning outcomes of the course unit;

10. Mode of delivery (face-to-face, distance learning);

11. Prerequisites and co-requisites;

12. Recommended optional programme components;

13. Course contents;

14. Recommended or required reading;

15. Planned learning activities and teaching methods;

\section{Assessment methods and criteria;}

17. Language of instruction;

18. Work placement(s).

In the following sections we propose additional and specific detail related to those three points $(9,13,14,15$, and 16).

\section{INTENDED LEARNING OUTCOMES AND CONTENTS OF THE COURSE UNIT}

Typically, an ILO is defined by a simple and direct sentence. Our template for an ILO adds four additional fields to that sentence. For better readability and completeness, we show part of a description for a humancomputer interaction course that follows our template. This is as second year course included in a computer science programme. Students have background in computer programming and in this course they learn user interface design and build functional prototypes. Here, we also show two additional sections, "Aims" and “Contents", as they are closely related to ILOs:

(Data proposed in the ECTS User's Guide)

\section{Aims}

This course presents the principles and methods that support the design of interactive systems. This knowledge should be applied by students in the development of hardware or software interfaces.

\section{Intended Learning Outcomes}

On successful completion of this course unit, the student should be able to:

LO 1: Analyse the usability of an interactive system.

Type: Skill.

Level: SOLO 4.

Main contents: 2.

Secondary contents: 1 and 3.

$$
\text { LO 2: }
$$

(...)

\section{Contents}
1. Basic Concepts.
2. Usability Principles and Rules.
3. Universal Design.
4. Design Process.
5. Task Analysis.
6. Interaction Styles.
7. InterfaceDevices.
8. Screen and Navigation Design.
9. Implementation Support.
10. Evaluation Techniques.
11. User Support.

Even before the list of intended learning outcomes and contents, the proposed template includes an "Aims" section. This section, should contain one or two small paragraphs that present the course unit by summarizing its general objectives.

Regarding the intended learning outcomes, the four additional fields are the following:

1. The Type; according to The European Qualifications Framework for Lifelong Learning (EQF) [2] this should be "Knowledge", "Skills", or "Competence";

2. The used taxonomy and the respective level, e.g. "SOLO 4" for the taxonomy by John Biggs [9] or BLOOM 2 for the Blooms's taxonomy [11] or the revised Bloom's taxonomy [12];

3. The list of the "main contents" this learning outcome uses;

4. The list of the "secondary contents" this learning outcome uses.

Field 1 aligns learning outcomes with the classification in EQF. Hence, it is also a way to align course outcomes with higher-level outcomes. Naturally, other similar alignments can be added, e.g. relating this learning outcome at course level to outcomes at programme or institutional level. Yet, this also implies an even more 
ambitious template, which in our opinion should be left to a second implementation step.

Field 2 is recommended practice for the specification of learning outcomes.

Fields 3 and 4 force an alignment between learning outcomes and a numbered list of course contents. In the authors' experience, this alignment is extremely important for two reasons:

1. It guarantees that all contents are really necessary, in the sense that they contribute to at least one learning outcome;

2. It acts as a facilitator and motivator for course designers that are using learning outcomes for the first time.

The alignment in the last point connects the "old" view of simply listing contents, to the "new" view that learning outcomes should come first. In this way, the newcomer to the design of learning outcomes can still see and even start from contents, while, at the same time, being forced to define learning outcomes. This is very important as a motivational factor, as it integrates the old and undesirable view of "contents first" with the objective of "learning outcomes first". The course designer can even start by listing the contents, but after each of the listed contents must be used by one or more learning outcomes as the main or secondary content. Also, it is especially important that the list of ILOs appears before the contents. This is a simple and effective way to value ILOs against contents.

It is probably quite obvious that not all contents are equally relevant for each learning outcome. Yet, instead of defining a (large) scale for specifying the degree of importance, we opted by a simpler approach, where for each outcome, each content is either a main one, a secondary one or it is simply not relevant enough to deserve mention.

Another alignment that should be present is the one between contents and the "Recommended of required reading". In this way, it becomes clear why each reading is relevant. For example, in each reading, this alignment can take the following form "contributes to contents 2 and 3". In the presented example, we have the following for each of the recommended readings:

\footnotetext{
Recommend Readings

1. Alan Dix, Janet Finlay, Gregory Abowd, Russell Beale, "Human-Computer Interaction", 3rd edition, Prentice Hall, http://www.hcibook.com/e3/, 2003.

Contributes to all contents, 1 to 11 .

2. Robert Bailey, "Human Performance Engineering", 3rd edition, Prentice Hall, 1996.

Contributes to contents 4, 5, 8, 10, and 11 .

3. Ivor Horton, "Ivor Horton's Beginning Visual C++ 2010", 1st edition, John Wiley \& Sons, 2010.

Contributes to content 9.
}

Together, these four parts (Aims, ILOs, contents, and readings) define what the course is, what the students should learn, the course themes, and what the students should read. Besides, the last three sections are specified in a interdependent way, thus reinforcing the course unit coherence. Now, we are going to present the specifications for how the course works and what the students and teachers should do. In that sense, the following section shows how to specify a second common alignment: between ILOs and assessment activities (e.g. $[8,9])$.

\section{From LEARNing OUtCOMES to Assessment ACTIVITIES}

In a less prescriptive way, the ECTS User's Guide alerts for the importance of connecting learning outcomes to assessment:

"The successful assessment of learning outcomes is the pre-condition for the award of credits to a learner. Therefore, statements of learning outcomes for programme components should always be accompanied by clear and appropriate assessment criteria for the award of credits, which make it possible to ascertain whether the learner has acquired the desired knowledge, understanding and competences” [1, p. 14]

Another important example is given by the report of the European Association for Quality Assurance in Higher Education (ENQA) [5], which also emphasizes the importance of connecting assessment to learning outcomes:

"Student assessment procedures are expected to (...) be designed to measure the achievement of the intended learning outcomes and other programme objectives;" [3, p. 17].

This is also recommended by many authors, to the point that it can be considered good general practice. To this end, we propose that for each assessment activity, the curricular unit description should specify which learning outcomes are being assessed. Additionally, each of the several assessment activities should be classified as "individual work" or "group work".

Schematically, and summing up the proposals in this section, we continue the presentation using the humancomputer interaction course as an example:

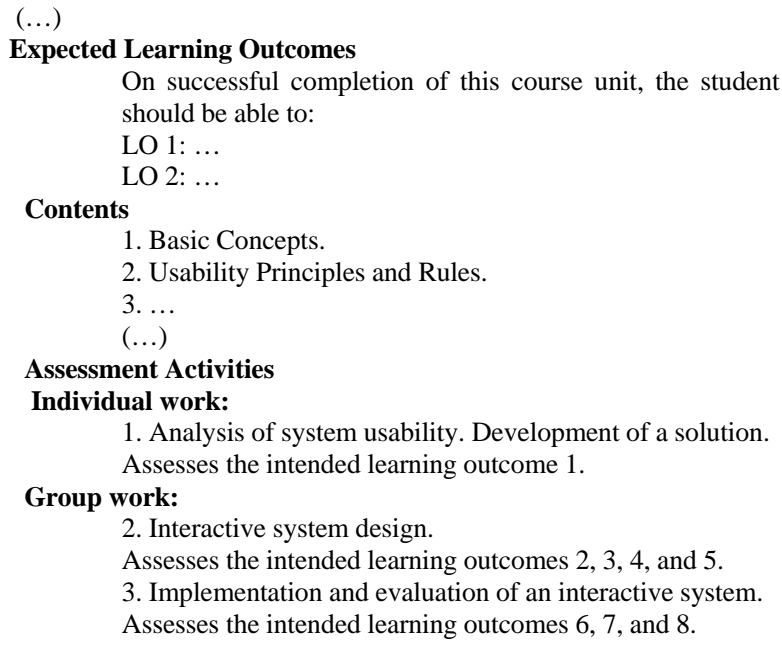

Note that for each assessment activity the teacher must state to which ILO that activity is relevant. This enforcement acts as a reality check for each assessment: implicitly, the teacher has to wonder about several questions, e.g.: "Why do I ask for this assessment?", "What will I be assessing?”, "Is it really necessary?”, "Is it similar to other assessments", "Am I assessing all the ILOs?”. This last question is especially relevant, as every learning outcome must be measurable, hence assessable and gradable. It is also well-known that students learn 
better and are better assessed if they are given multiple vehicles: e.g. readings, videos, practice, discussion, etc.. For that reason, each teacher has to specify the type of assessment activity. In other words, the teacher has to classify the assessment activity. Little assessment variability should work as a warning as it can promote surface learning and unfairness among students. Naturally, this is even more important for teaching and learning activities, which are discussed in the next section. The following section also shows how to specify the alignment between assessment and teaching and learning activities.

\section{From AsSESSMENT to TEACHING AND LEARNING ACTIVITIES}

Teaching and Learning activities should prepare the student for the respective assessment. We propose that those activities be grouped by type and/or context. Those types and contexts should be provided as a list to choose from. This list can eventually motivate teachers to try new assessment methodologies. Typically, the list should be open, as teachers are usually free to choose the kind of assessment activities for their students. Continuing our template, we would add the following structure (with exemplary content):

\section{Teaching and Learning Activities}

\section{Group work:}

Designing of an interactive system.

Prepares for assessment activities 2, 3, and 4.

Large class:

Presentation and discussion of course topics.

Prepares for all assessment activities.

\section{Individual work:}

Analysis of an interface usability and solution proposal.

Prepares for assessment activities 1 and 4.

\section{Autonomous research:}

Research about additional topics.

Prepares for assessment activities 2 and 3.

Here, we have exemplified with four types/contexts for teaching and learning activities. As with assessment activities, the specification of the "types" of activities should increase motivation to increase variability thus fostering reflective teaching and, hopefully, improved student learning.

An important aspect is that the teaching and learning activities must be aligned with the assessment activities. It should be clear that their objective is to prepare students for the assessment activities. Hence, the specification of these connections promotes additional reflection from the course designer and guarantees that no proposed activity is unnecessary for the assessment. This offers an "automatic" answer to the classical student question, which is usually a variation of "What is the use of this?" or "Why am I doing this?". Now, it should be clear that what the student does is preparation for the assessment activities, which, in turn, measure the accomplishment of all the ILOs.

\section{FROM ASSESSMENT TO GRADING}

Finally, we propose the use of a stepwise grading approach. Each assessment activity should be graded accordingly to a mixture of summative and subtractive criteria. The subtractive criteria should be used when important but simple requirements are not complied. For example, in computer programming, code formatting by itself can be seen as necessary but not sufficient to contribute to a better grade in a given assignment. Additionally, the summative requirements can be divided in two steps: essential and non-essential. The nonessential are only counted if and only if the essential ones are totally accomplished. This avoids the temptation to deliver a fully incomplete work that "does" a bit of everything but fails to accomplish anything meaningful. Finally, the higher grades should be achieved only if the student adds something more that is not specified, thus valuing and encouraging creativity. A much more complete explanation for this stepwise grading method was already presented in [13].

\section{CONCLUSIONS}

Taking advantage of some of the numerous sources already available about course design and course description, especially the ECTS User's Guide [1] and the work by Biggs and Tang [3], this paper presented a proposal for a course description template that expands and details the data and general advice contained in the ECTS User's Guide. To that end, it adds further detail to each major component in the curricula (learning outcomes, readings, assessment activities, teaching and learning activities, and grading) and emphasizes several alignments between the curricula components and between those and the EQF document. All these dependencies and additional data contribute to a more complete, coherent, and useful course descriptions as they induce additional reflection from the teacher, in the role of course designer. In the end, the here proposed template should provide improved course descriptions at all levels and for all the stakeholders, while being especially useful for students.

\section{ACKNOWLEDGMENT}

This work was partially financed by Portuguese Agency "FCT - Fundação para a Ciência e a Tecnologia" in the framework of project PEst-OE/EEI/UI0066/2011

\section{REFERENCES}

[1] European Communities (2009, February 6) ECTS Users's Guide [Online]. Available: http://ec.europa.eu/education/lifelonglearning-policy/doc/ects/guide_en.pdf.

[2] European Communities (2008), The European Qualifications Framework for Lifelong Learning (EQF) [Online]. Available: http://ec.europa.eu/education/pub/pdf/general/eqf/broch_en.pdf

[3] ENQA (2009), Standards and Guidelines for Quality Assurance in the European Higher Education Area [Online], $3^{\text {rd }}$ edition. Available: http://www.enqa.eu/pubs_esg.lasso.

[4] Nusche, D., "Assessment of Learning Outcomes in Higher Education: A Comparative Review of Selected Practices”, OECD Education Working Paper No. 15, Feb. 2008, available at http://www.oecd.org/australia/ 40256023.pdf, accessed on 2012/12/02.

[5] “Using Learning Outcomes”, European Qualifications Framework Series: Note 4, European Union, 2011, available at http://ec.europa.eu/ education/lifelong-learningpolicy/doc/eqf/note4 en.pdf. Accessed on 2012/12/02.

[6] The Bologna Declaration of 19 June 1999, Joint declaration of the European Ministers of Education, available at http://www.bologna-berlin2003.de/pdf/bologna_declaration.pdf, assessed on 2012/12/02. 
[7] Kennedy, Declan, Hyland, Aine, and Ryan, Norma (2006) 'Writing and Using Learning Outcomes: A Practical Guide' in: EUA, Bologna Handbook. Making Bologna Work. Berlin: European University Association http://www.bologna.msmt.cz/files/learningoutcomes.pdf Presented to the Bologna Seminar: Using Learning Outcomes (July 2004, Edinburgh) http://www.bologna-bergen2005.no/EN/Bol_sem/Seminars/04070102Edinburgh/040620LEARNING_OUTCOMES-Adams.pdf .

[8] L. D. Fink. Creating Significant Learning Experiences: An Integrated Approach to Designing College Courses. Jossey-Bass, 2003.

[9] J. Biggs and C. Tang. Teaching for Quality Learning at University. Open University Press, 3rd edition, 2007.

[10] Barros, J.P., Gomes, L., and Garcia, L., Towards a Complete Description for Individual Course Units - A follow-up to the Bologna proposals, in Proceedings of the International Conference on Interactive Collaborative Learning, Villach, Austria, 2012.

[11] Bloom, B.S., Engelhart, M.D., Furst, E.J., Hill, W.H. and Krathwohl, D.R. (1956) Taxonomy of educational objectives Handbook 1: cognitive domain. London, Longman Group Ltd.

[12] Anderson, L.W., Krathwohl, D.R., Airasian, P.W., Cruikshank, K.A., Mayer, R.E., Pintrich, P.R., Raths, J. and Wittrock, M.C. (eds.) (2001). A taxonomy for learning and teaching and assessing: A revision of Bloom's taxonomy of educational objectives. Addison-Wesley Longman.
[13] João Paulo Barros. 2010. Assessment and grading for CS1: towards a complete toolbox of criteria and techniques. In Proceedings of the $10^{\text {th }}$ Koli Calling International Conference on Computing Education Research (Koli Calling '10). ACM, New York, NY, USA, 106-111.

\section{AuTHORS}

João Paulo Barros is with the Instituto Politécnico de Beja, Escola Superior de Tecnologia e Gestão, Beja, Portugal and UNINOVA-CTS, Monte de Caparica, Portugal (joao.barros@ipbeja.pt)

Luís Gomes is with UNINOVA-CTS, Monte de Caparica, Portugal and ${ }^{3}$ Universidade Nova de Lisboa, Faculty of Sciences and Technology, Monte de Caparica, Portugal (lugo@fct.unl.pt)

Luís Garcia is with the Instituto Politécnico de Beja, Escola Superior de Tecnologia e Gestão, Beja, Portugal (luisbgarcia@ipbeja.pt)

This article is an extended and modified version of a paper presented at the IGIP2012 conference, held 26 - 28 September 2012, in Villach, Austria. Received 3 December 2012. Published as resubmitted by the authors 28 January 2013. 